\section{CONTINUOUS IMPROVEMENT EFFORT SHOWN TO BE WORTH ITS WEIGHT IN BLOOD}

Wade Stewart, Tom Stipe. Penn State Hershey Medical Centre, US

\subsection{6/bmjoq-2017-IHI.2}

Background The Department of Pathology identified an opportunity to optimise specimen turn-around-time (TAT) to meet customer expectation (patient and providers). More than 10\% of the blood specimen are not resulted within the 60 min customer expectation. The team focused on the top five specimen analytes representing over $80 \%$ of the volume through the lab. The team followed the DMAIC process to utilising Lean and Six Sigma tools to identify predicted and unpredicted opportunities in specimen processing.

Objectives Optimised specimen turn-around to create a process that meet customer expectation of $=60$ mins $95 \%$ of the time. Methods Implementation of project improvements by the team included a daily shift huddles using a common format with visual controls, supervisor standard work to view huddles weekly, elimination of multiple non-value activities (e.g., specimen initializing), level loading, cross-training, and the identification of a daily 'Flow Master' to communicate issues in realtime. These combined improvements yielded significant TAT reductions in all 5 tests. The improvements in TAT among the five test ranged from $8 \%$ to $26 \%$.

Results

\begin{tabular}{lllll}
\multicolumn{5}{l}{ Abstract 838 Table 1} \\
\hline Test & $\begin{array}{l}\text { TAT Mean } \\
\text { Before }\end{array}$ & $\begin{array}{l}\text { TAT Mean } \\
\text { After }\end{array}$ & $\begin{array}{l}\text { Mean P- } \\
\text { value }\end{array}$ & $\begin{array}{l}\text { \% TAT } \\
\text { Improv }\end{array}$ \\
\hline HGB & 28.08 & 20.73 & 0.001 & 26 \\
K & 44.70 & 39.56 & 0.001 & 11 \\
pH & 12.51 & 11.34 & 0.001 & 9 \\
PTT & 34.94 & 31.95 & 0.001 & 9 \\
TNI & 58.80 & 51.75 & 0.001 & 12 \\
Overall & 37.16 & 31.79 & 0.001 & 14 \\
\hline
\end{tabular}

Conclusions Since the implementation of solutions the laboratory continues to track and maintain improvements. A control plan is in place to evaluate laboratory performance when it is out of specification and action is required. This project clearly demonstrated that improvements can be magnified when used in combination with Lean Six Sigma methodology and tools.

\section{ROUTINE SUPPLEMENTATION OF PROBIOTICS FOR PREVENTION OF NECROTIZING ENTEROCOLITIS IN PREMATURE INFANTS - A QI PROJECT}

${ }^{1}$ Asaph Rolnitsky, 'Eugene $\mathrm{Ng},{ }^{2}$ Yasmin Shama, ${ }^{1}$ Maren Garche, 'Michael Dunn. ${ }^{1}$ Sunnybrook Health Sciences Centre, Canada; ${ }^{2}$ SickKids, Canada

\subsection{6/bmjoq-2017-IHI.3}

Background Necrotizing enterocolitis (NEC) carries high rates of mortality and morbidity in perterm infants. Our NEC rates over 6 years, were in higher quartiles of the Vermont-Oxford Network and prompted an improvement project.

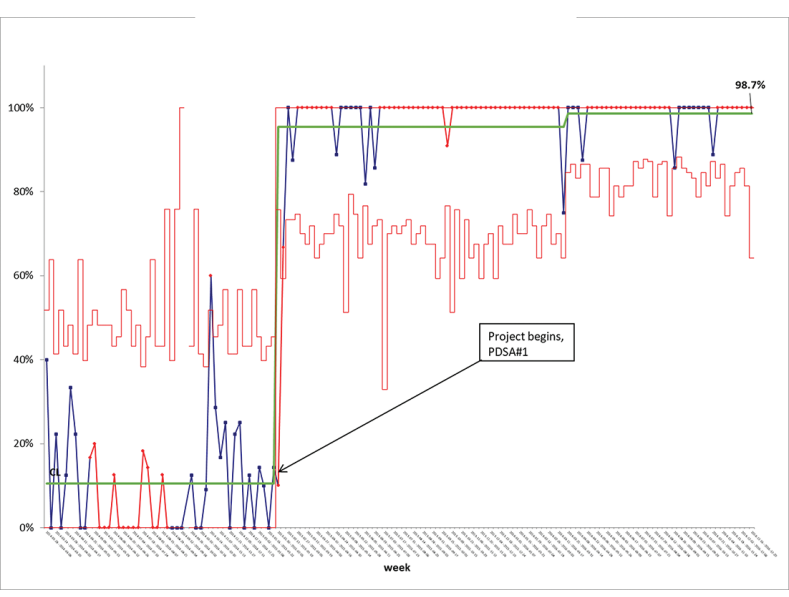

Abstract 841 Figure 1 p Chart: $\%$ infants $<33$ wks given biogaia

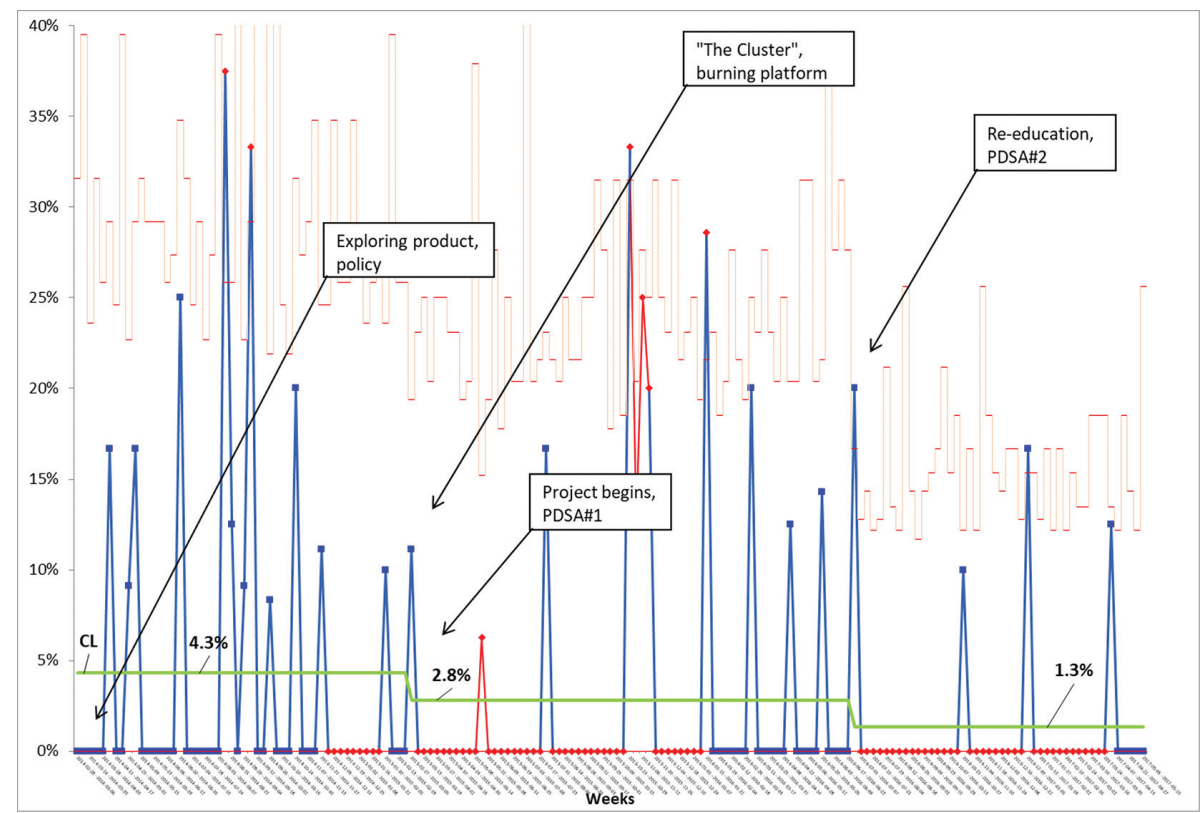

Abstract 841 Figure 2 p Chart: NEC rates, infants $<33$ wks GA 
Objectives To reduce NEC rates by $30 \%$ from $4.5 \%$ to $3 \%$ by $3 /$ 2016 in $<33$ weeks infants admitted in Sunnybrook NICU.

Methods Multi-professional team used fishbone analyses, process maps, literature review and compliance with hospital Infection Prevention unit. A product was selected (BioGaia, Lactobacillus reuteri; Ferring, Sweden). A policy written and approved. As a forcing mechanism, order for probiotics added to admission orders set. We gave education to staff, parents. We started after a cluster of cases ('burning platform'). PDSA\# 1 on the first baby was in 2/2015. After first month, issues were addressed, then spot audits assured continuing compliance. Measures: Outcome measures: NEC in infants $<33$ wk GA, (>=stage 2), Sepsis, Mortality. Secondary outcomes: Sepsis evaluations, Feeding intolerance, Days NPO, Growth rate/week, Antibiotics days, TPN days, Formula days. Process measures: Compliance rate, Probiotics days. Balancing measures: Sepsis, Feeding intolerance

Results One year before (planning periods, 330 infants), and two years into implementation (745 infants). NEC rates declined from $4.3 \%$ to a current rate of $1.3 \%$. P-chart of NEC show a sustained reduction, P-chart of compliance shows a sustained compliance. Other outcomes detailed in Table 1. No significant baseline differences.

Conclusions Our QI project used QI tools - teamwork, RCA, aim statement, drivers, standardisation, forcing mechanisms, education, PDSA, and SPC. All supported a feasible, effective, safe, and sustained improvement. Findings are consistent with previous RCTs.

Abstract 841 Table 1 Baseline charactreristics and outcomes

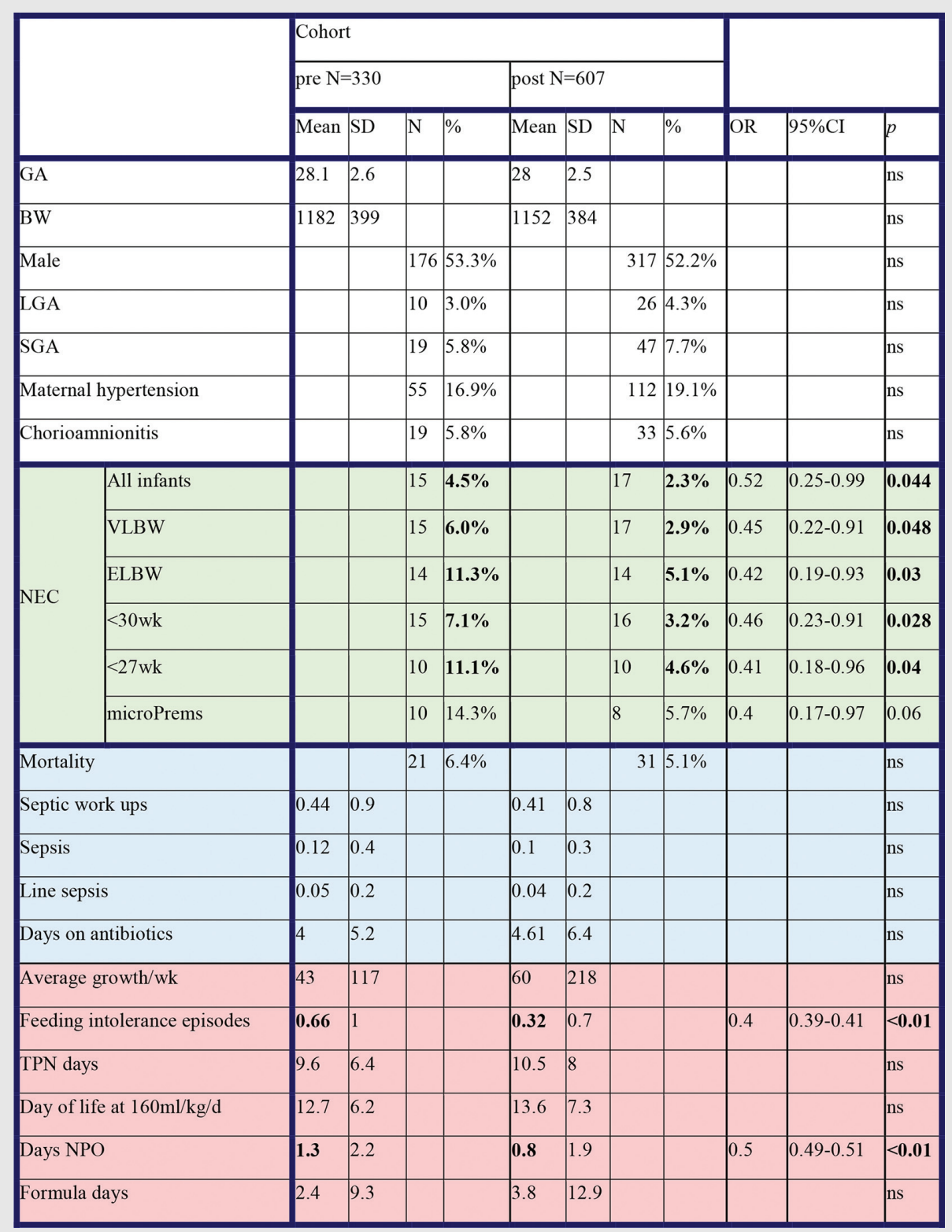

